\title{
In Memoriam: Diarmuid Ua Conaill
}

\section{Pioneer of the Health Informatics Society of Ireland (HISI), and Long-standing Ireland Representative to the International Medical Informatics Association (IMIA), Secretary and Board Member of IMIA}

There are people who are both original and incisive thinkers and who also choose to contribute selflessly to the painstaking but essential work of professional organizations. Diarmuid Ua Conaill was such a person. It is with great sadness that we report that he passed away on July 2, 2018 surrounded by his loving family at St. Francis Hospice, Raheny, Co. Meath, Ireland.

Diarmuid has been a most valued and trusted member of the International Medical Informatics Association (IMIA), much appreciated as IMIA Secretary and IMIA Board Member from 2003 to 2009. He had earlier been Chair and Treasurer, and long-standing Representative of HISI (Healthcare Informatics Society of Ireland) and its predecessor to IMIA (1980 - 2009).

As Secretary of IMIA, Diarmuid was instrumental in accurately recording and archiving the IMIA Board and General Assembly Meeting Proceedings as well as related documents. His systematic assembly, indexing, and archiving of IMIA material has been critical for maintaining the continuity of the institutional memory and we are forever in his debt for his thoughtful contributions to the IMIA History Project on International Biomedical and Health Informatics.

Diarmuid was instrumental in setting up the Healthcare Informatics Society of Ireland (HISI) after being inspired by IMIA activities at MedInfo 95 in Vancouver. HISI started as a section within the Royal Academy of Medicine of Ireland, which was merged with the IMIA-related predecessor Healthcare Specialist Group of the Irish Computer Society. HISI was then accepted as Ireland's official society at the IMIA General Assembly in Sydney in 1997, and Diarmuid continued as representative to IMIA for the new society.
Diarmuid Ua Conaill's experience with biomedical and health informatics, however, goes back much further - to the early days when calculators and computers were used in biomedicine and healthcare, making him a pioneer in the profession. He was trained as a biochemist at University College (part of the National University of Ireland) in Cork (UCC). In his first research position at St. Joseph's Children's Hospital in Dublin in 1963 he started using electromechanical calculators to statistically analyze the results of biochemical tests. From this early introduction to automated data analysis, he went on, after completing a Master of Science (also at UCC), to head the Biochemistry Laboratory at Dublin's Mater Misericordiae Hospital, where, from 1970, he chaired the Computer Committee and was widely consulted throughout Ireland and the UK for his knowledge and skills in assessing computing systems for both laboratory and clinical applications.

Diarmuid was fascinated by computers, by computing, and by how computers can help in biomedical research and healthcare management. He started programming on a Casio electronic calculator (with only 20 program steps!), moved on to a Wang PC2 where he learned BASIC, and then to a PDP8 - still with a teletype interface. In 1975, he attended a summer school in medical informatics organized by Peter L. Reichertz in Hannover, widening his circle of contacts internationally as well as at home, so that shortly after he joined the newly-formed Healthcare Specialist Group (HSG) of theIIrish Computer Society. In 1980 he became the Irish Representative to IMIA and, as noted above, remained in this capacity until 2010 after the HSG was supplanted by HISI: a 30-year record for our organization!

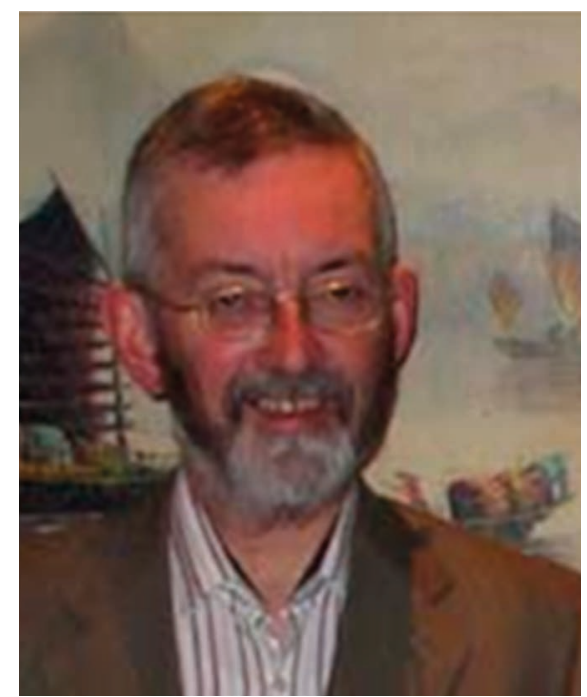

The Irish Government sent Diarmuid with a team of experts to the USA in 1983 to evaluate computer usage in US hospitals as part of a planned computerization of all Irish hospitals. Shortly after, Diarmuid joined the Liaison Committee on Hospital Laboratory Computing for the Irish Department of Health, became its Chair, and wrote the first draft of the influential report on Recommended Standards for Hospital Laboratory Systems, published in 1986. During this time, work was carried out to integrate results from the SMA-12 multi-analyzer with other hospital systems, including the TelePath laboratory system from Shared Medical Systems Corporation (SMS), as well as the SMS hospital patient information system. He pioneered an Order Communications and Results Reporting system (OCRR), considerably reducing laborious manual data entry and resulting errors. 


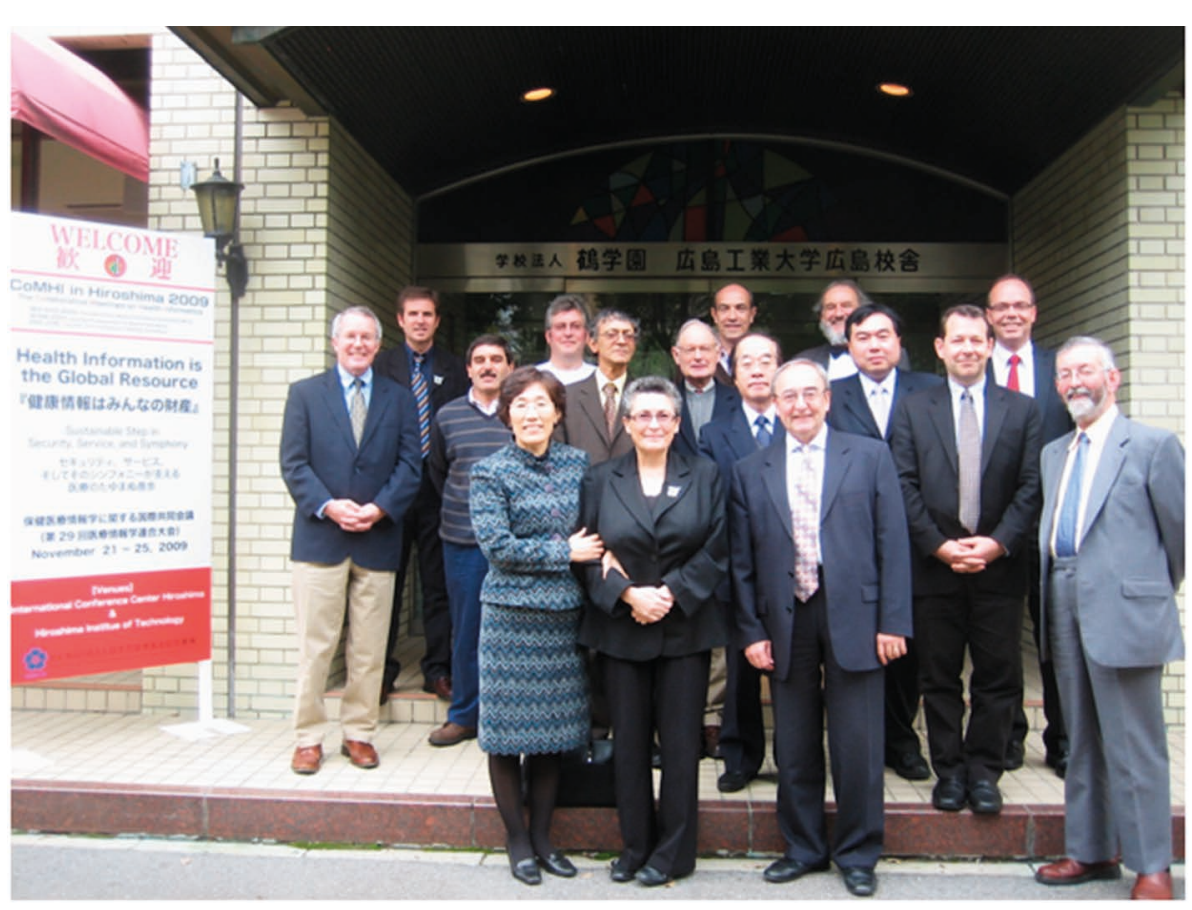

Fig. 2 Photo of the IMIA Board, including Diarmuid Ua Connaill (far right) taken outside the meeting venue during the 6th APAMI Conference (held with CoMHI: Health Information is the Global Resource) in Hiroshima, Japan, November 2009.

In 2003 Diarmuid retired from Mater Misericordiae Hospital and set up a consultancy, advising on government procurement of hospital laboratory computer systems, and on interfaces between the nation-wide HealthLink system and the TelePath system that were still without OCRR. The same year, Diarmuid became Secretary of IMIA, serving until 2009, under Presidents K.C. Lun, Nancy M.
Lorenzi, and Reinhold Haux, and Executive Directors Steven Huesing and Peter Murray. He worked on the Statutes of IMIA and drafted revisions to bring them in line with the actual practices. He joined the IMIA Archives Taskforce and continued on the Executive Committee of HISI until 2012. When he stood down from HISI, the Society awarded him the O'Moore Medal for his contributions.
It is with great sorrow that we all mourn the passing of Diarmuid. He was a good friend, a tireless and meticulous Secretary of IMIA, and a wonderful host to the IMIA Board when, at the invitation of HISI, the IMIA Board held its April 2009 meeting in Dublin. The venue was the beautiful Ely House, Dublin 2, one of the best preserved Georgian buildings in Dublin, courtesy of the Knights of Saint Columbanus. In recognition of this honor, HISI organized a special all day conference on the $23^{\text {rd }}$ April, themed 'ICT in Healthcare - National \& International Developments and Experiences', to which IMIA Board members contributed. Diarmuid organized all the activities, and took us on an unforgettable tour of the Newgrange Neolithic Passage Tomb in County Meath - dating from around 2,300 BC, as well as a wonderful IMIA dinner including traditional Irish music and dancing. He guided us around Dublin and his helpful and thoughtful hospitality was in the best tradition of IMIA with its concerns of putting people and their care first - even as we focus on the challenges of informatics. We will all sorely miss him but he will be well remembered for his accomplishments, kindness, and outstanding contributions to our profession, HISI, and the international association of Medical and Healthcare Informatics Societies that is IMIA.

Casimir A. Kulikowski, Reinhold Haux, Nancy M. Lorenzi, Otto Rienhoff 